\title{
Direito e Participação Social
}

\begin{abstract}
RESUMO
SPECIE, P. Direito e Participação Social. 2015. 164p. Tese (Doutorado) - Faculdade de Direito, Universidade de São Paulo, São Paulo, 2015.

Esta tese é um estudo sobre a arquitetura jurídica das Instituições Participativas (IPs) em políticas públicas no Brasil, desde a Constituição brasileira de 1988. A hipótese geral do trabalho é que a legislação que estrutura e resulta das IPs, como as duas principais formas institucionalizadas de participação social em políticas públicas - conselhos e conferências nacionais -, constitui estrutura jurídica relevante destinada à análise da legitimidade democrática resultante de práticas de democracia participativa no interior da administração pública brasileira. A tese se organiza em três partes principais (i) introduz a participação social como uma política pública em si, caracterizada por arranjos jurídicos especiais para a gestão pública brasileira e resultante da implementação de uma reforma participativa do Estado brasileiro, sobretudo a partir dos anos 2000; (ii) delineia três dimensões de análise da relação entre "direito e participação social", a partir das quais qualquer IP poderia ser juridicamente descrita - como direito à participação (dimensão substantiva), regras de participação (dimensão estruturante), e direitos da participação (dimensão instrumental) - a fim de enfatizar a legitimidade funcional do aparelho do Estado participativo, vinculando o fortalecimento da participação, com atenção à relação entre governabilidade (capacidade política) e governança (capacidade administrativa), identificada por meio de regras que estabelecem IPs no poder executivo federal; e, por fim, (iii) investiga como a política pública ambiental tem desenvolvido uma moldura jurídica para conselhos e conferências nacionais ainda que não tenha sido guiada previamente por uma "Política Nacional de Participação Social" (PNPS) nos moldes do Decreto Presidencial 8.243/2014, que a instituiu.
\end{abstract}

Palavras-chave: Direito e Políticas Públicas, Instituições Participativas, Conselhos ambientais, Conferências Nacionais do Meio Ambiente. 


\section{RÉSUMÉ}

SPECIE, P. Droit et Participation Sociale. 2015. 164 p. Thèse (Doctorat) - Faculté de droit de l’Université de São Paulo, São Paulo, 2015.

Cette thèse étudie l'architecture juridique brésilienne concernant les institutions participatives (IPs) destinées à la formulation des politiques publiques depuis la Constitution brésilienne de 1988. L'hypothèse générale de l'étude est la suivante: l'actuelle législation sur les IPs, sous ces deux principales formes institutionnalisées pour la participation sociale (conseils et conférences nationales, notamment sur la politique environnementale), est appropriée pour l'analyse de la légitimité démocratique résultant des pratiques de démocratie participative au sein de l'Administration publique brésilienne. La thèse a trois principales étapes d'analyse (i) elle introduit l'idée que la participation sociale est une politique publique per se, caractérisée par des arrangements institutionnels spéciaux destinés à la gestion publique qui résultent de l'implantation d'un l'État participatif au Brésil, principalement après depuis les anneés 2000; (ii) cette étude décrit trois dimensions juridiques pour la relation «droit et participation sociale », à partir desquelles toute autre IP pourrait être décrite légalement - en tant que droit à la participation (dimension substantive), règles procédurales pour la participation (dimension structurelle) et droits de participation (dimension instrumentale) - afin de souligner la légitimité de l'organisation de l'État participatif, reliant le renforcement de la participation, avec une attention sur la relation entre la dimension structurante de gouvernabilité (capacité politique) et la gouvernance (capacité administrative), identifiés par les règles établies pour les IPs crées par le pouvoir Exécutif; et, finalement, (iii) cette thèse analyse la façon dont la politique publique sur l'environnement a établi un encadrement juridique pour les conseils et les conférences nationales, bien qu'elle n'est pas préalablement guidée par la «Politique nationale pour la participation sociale », qui a été édictée par le décret présidentiel 8,243/2014.

Mot-clés: Droit et Politique Publique, Institutions Participatives, Conseils, Conférences Nationales sur l'environnement. 


\begin{abstract}
SPECIE, P. Law and Social Participation. 2015. 164p. Thesis (Doctoral) - Faculdade de Direito, Universidade de São Paulo, São Paulo, 2015.

This thesis is a study on the Brazilian legal architecture concerning the participatory institutions (PIs) for public policies, since Brazilian Constitution of 1988. The general hypothesis of the study is that legislation designing and resulting from PIs such as the two main institutionalized forms of participation on public policies - councils and national conferences - focused on thematic examples (eg. environmental policy), points out an appropriate fashion for the analysis on democratic legitimacy structuring participatory democracy practices within the Brazilian public administration. The thesis takes three main steps (i) introduces the social participation as an overall public policy, characterizing special institutional arrangements for the Brazilian public management and suggesting a Participatory State Reform in Brazil, mainly after the 2000s; (ii) outlines three dimensions of viewing "law and social participation", from which any particular PI could be lawfully described - the right to participation (substantive dimension), procedural rules for participation (structuring dimension) and rights from participation (instrumental dimension) - in order to stress the focus on the legitimacy of the State participatory apparatus, linking the strengthening of participation with attention to a preliminary balance on the structuring dimension of governability (political capacity) and governance (administrative capacity), identified through the rules establishing PIs in the federal executive branch of government; and (iii) investigates how environmental public policy has developed such legal framing for councils and national conferences even if it has not been previously guided by a "National Social Participation Policy", as enacted by Presidential Decree 8,243/2014.
\end{abstract}

Keywords: Law and Public Policies, Participatory Institutions, Councils, National Environmental Conferences 


\section{INTRODUÇÃO}

Em trabalhos recentes, uma série de estudos do Instituto de Pesquisa Econômica Aplicada (IPEA) ${ }^{1}$, seguindo as pesquisas de autores como Pires e Vaz (2012), Avritzer (2008, 2011) e Lavalle (2011b) apontam o boom da participação social ${ }^{2}$ em nível federal no Brasil, durante as últimas duas décadas, a partir da promulgação da Carta Constitucional de 1988. A expansão das instituições participativas (IPs) do nível local para o nacional é especialmente destacada por Avritzer (2011, p. 13) como marca da última década. Em contraposição às concepções ultrapassadas de "instituições políticas" alcançadas pela teoria democrática até final do século $\mathrm{XX}$, restritas a parlamentos, partidos e poder judiciário, opondo "participação" a "institucionalização", adotamos a formulação de Avritzer (2008, p. 45) para entender por instituições participativas todas "as formas diferenciadas de incorporação de cidadãos e associações da sociedade civil na deliberação sobre políticas".

Os números da participação e os diversos espaços participativos indicados pelos autores $^{3}$ colocam o Brasil como referência de experiências inovadoras em instâncias de participação democrática (LAVALLE, 2011a). Segundo Milani (2008, p. 556):

O caso do Brasil é particularmente importante, não apenas por ser palco de um dos experimentos participativos mais citados na literatura (o orçamento participativo de Porto Alegre), mas por ter integrado o princípio participativo em sua Constituição.

\footnotetext{
${ }^{1}$ O IPEA, por meio de sua Diretoria de Estudos e Pesquisas sobre o Estado, Instituições e Democracia (Diest/Ipea) em parceria com Secretaria-Geral da Presidência da República (SG/PR), desde 2010, estabeleceu o tema da participação social como central em sua agenda de pesquisas. As dezenas de publicações sobre os mais variados aspectos de instituições participativas, com destaque para extensivas pesquisas sobre Conselhos Nacionais e Conferências de Políticas Públicas, encontra-se disponível online em: <http://www.ipea.gov.br/participacao/>. Acesso em: nov. de 2014.

2 A expressão "participação social" (que também traz referência, entre outras, às expressões "participação cidadâ" e "participação popular") será usada como opção metodológica para estabelecer uma ponte com a construção da "Política Nacional de Participação Social" (PNPS), sistematizada durante a última década pela Secretaria-Geral da Presidência da República (SG/PR), fazendo referência aos principais processos de participação de cidadãos, coletivos, movimentos sociais, suas redes e suas organizações; de cidadãos, organizações da sociedade civil na Administração Pública Federal, desenvolvidos desde a Constituição de 1988.

${ }^{3}$ Conselhos gestores de políticas, conferências temáticas nacionais, orçamentos participativos (incluindo participação nos planos plurianuais - PPAs), ouvidorias, instâncias de consultas individuais e coletivas, presenciais e por meio da Internet (sobretudo via instrumentos de web 2.0 - com interatividade), audiências públicas, entre outros mecanismos mais ou menos institucionalizados como mesas de diálogos, grupos de trabalhos, câmaras, comissões, comitês, etc.
} 
Após análises que demonstraram a explosão em quantidade e de diferentes modelos de IPs, os estudos se voltam aos questionamentos sobre o que esperar quanto aos seus resultados, em especial, sobre a qualidade democrática dessas experiências. Nesse sentido, o presente trabalho busca como objetivo geral apresentar uma contribuição para o papel do direito na promoção de legitimidade democrática pela forma como institucionaliza IPs que integram a Administração Pública Federal. ${ }^{4}$ Assim, propõe-se uma leitura da arquitetura jurídica que cria (objetivo das regras), estrutura (regras do jogo) e resulta (objetivos temáticos, de ação) da participação social, nos últimos 25 anos no Brasil. Como objetivo específico, o trabalho se volta para a análise da moldura jurídica das IPs presentes nas políticas públicas ambientais, em especial: as quatro conferências nacionais de políticas públicas ambientais realizadas até hoje e dois conselhos ambientais nacionais vinculados ao Ministério do Meio Ambiente (Conselho Nacional do Meio Ambiente - Conama; e o Conselho Nacional de Recursos Hídricos - CNRH).

Como eixo condutor, ao centrar-se na análise dos mecanismos de criação, funcionamento e resultados jurídicos da participação, o estudo sobre a qualidade do exercício da democracia ao longo do tempo revela tendências de transformações do Estado e do direito contemporâneo.

Enquanto o marco teórico da análise sobre os modelos de democracia impulsionados pelas IPs se situa entre a ótica dos modelos participativos ${ }^{5}$ e deliberativos ${ }^{6}$, os modelos de Estado que promovem políticas de proximidade (ROSANVALLON, 2008), por meio da participação social, se aproximam das formulações correspondentes a uma sociedade policêntrica (JESSOP, 2001). Esse modelo de sociedade, apesar de intensificar a condições de complexidade das ações sociais, não abre mão de um Estado “eficaz” (FERRACI; WASMER, 2012).

\footnotetext{
${ }^{4}$ Resultados parciais da pesquisa para a tese foram discutidos durante dois congressos internacionais de 2014: (i) em abril, na cidade de Coimbra (Portugal), no VII Congresso da Associação Portuguesa de Ciência Política - APCP, organizado pela Universidade Coimbra; e (ii) em julho, na cidade de Montreal (Canadá), no $23^{\circ}$ Congresso Mundial de Ciência Política (IPSA).

${ }^{5}$ Cf. Held (2006, p. 215); Nobre (2004, p. 33).

${ }^{6}$ V. Nobre (2004, p. 98) e, em especial, o marco teórico que aprofunda o modelo habermasiano (cf. Habermas, 1998 e 1997) a partir de algumas de suas interpretações (NOBRE e TERRA, 2008; MATTOS, 2006, pp. 31 e 202; VITALE, 2004).
} 
Nesse sentido, as configurações de ordens normativas pluralistas tendem a contestar as concepções tradicionais de racionalidades jurídicas, lastreadas exclusivamente na lógica formalista da legalidade e da hierarquia sustentam uma concepção de ordem Estatal uniforme e coerente ${ }^{7}$. Ordens pluralistas fazem emergir um direito flexível, que opera em formato de rede ou de pirâmide. ${ }^{8} \mathrm{Se}$, por um lado, a racionalidade jurídica é caracterizada pela incerteza, relativismo e imprevisibilidade, decorrentes da vulnerabilidade a que o direito se tornou suscetível como objeto de barganha política característica da crise do Estado Moderno; por outro lado, sem necessariamente substituir por completo a construção moderna do direito ${ }^{9}$, a racionalidade jurídica contemporânea se caracteriza pela lógica de intercompetências e internomatividades (CHEVALIER, 2008) ${ }^{10}$.

A partir desse contexto, o presente trabalho se afasta da ideia de analisar um "Direito da Participação Social" para se aproximar da relação entre "Direito e Participação Social", por meio de modelos de arquiteturas jurídicas que caracterizam a institucionalização da política de Política de Participação Social. Assim, políticas públicas que incluem a participação por meio de regras podem revelar direitos à participação (participação como objetivo das regras), em diferentes níveis de participação (por ex. acesso à informação, consulta, deliberação) e distintas etapas do ciclo de políticas públicas ou de gestão (ex. formulação ou monitoramento). Ao mesmo tempo, os desenhos institucionais de IPs, ao estabelecerem critérios de elegibilidade, paridade ou rotatividade para a participação, traduzem regras de participação que organizam o funcionamento da relação entre Estado e sociedade civil (ex. de larga escala ou de grupos de especialistas, como permanente ou periódico). Por fim, IPs, que por meio da participação definem instrumentos normativos que orientam a ação do Estado, revelam

\footnotetext{
${ }^{7}$ Sobre as tendências das formas e funções do direito no século XXI, o ponto de partida são as formulações de Faria (1993, 2000, 2008, 2011) e Arnaud (2003, p. 87).

${ }^{8}$ Cf. Kerchove (2002, p. 75).

${ }^{9}$ Cf. Morand (1999).

${ }^{10}$ A noção de internormatividade ou interlegalidade foi desenvolvida também por Boaventura de Souza Santos, mas em abordagem diversa da utilizada neste trabalho. Santos (1995) analisou-a da perspectiva do pluralismo jurídico, em que distintos espaços jurídicos operam e interagem, simultaneamente, em diferentes escalas. Em seu famoso estudo sobre o "direito de Pasárgada", realizado no Brasil, Santos (1977) explorou este fenômeno a partir da complexa interação entre o direito estatal ("direito do asfalto") e a normatividade criada pela própria comunidade, tomando-a como uma das expressões da luta de classes no país. De modo distinto, o conceito de internormatividade não será usado como expressão do pluralismo jurídico entre distintas ordens normativas, nem conterá o viés ideológico empregado por este autor.
} 
direitos da participação (regras como objetivos da participação) como diretrizes, resoluções, recomendações, termos de compromisso, etc.

Tal estrutura parece ser imprescindível para a organização dos diferentes grupos sociais. Ela confere poder a atores sociais no processo de tomada de decisão por meio de instrumentos jurídicos, bem como determina suas condições de influência na orientação da ação do Estado. Analisar a qualidade democrática de IPs trata-se, assim, de compreender como as regras, não restritas a atos normativos formais (leis, decretos e portarias), definem quem, quando e como participa na gestão pública, de modo a criar condições para que interesses múltiplos e conflitantes encontrem caminhos para que decisões políticas se traduzam em políticas públicas.

Em que pese a avaliação crítica da eficácia e da efetividade ${ }^{11}$ das políticas públicas resultantes de IPs como fundamental para a compreensão da qualidade democrática da

\footnotetext{
${ }^{11}$ As noções de eficácia e efetividade são tratadas de modo diferente desde as perspectivas do direito e das políticas públicas. Segundo Faria (2000, p. 125), a avaliação dos resultados efetivos de uma norma em um dado contexto ensejou, na literatura jurídica, a distinção conceitual entre eficácia em sentido amplo e eficácia em sentido estrito. Nas palavras do autor: "Também chamada de efetividade, a primeira se refere às normas capazes de obter a realização da conduta nelas prevista, sempre que isso implique a consecução dos objetivos pretendidos pelo texto legal. A segunda se refere à norma que, além de conseguir o cumprimento do comportamento originalmente previsto, obtém igualmente a concretização dos objetivos pretendidos por esse mesmo texto." Sobre esse tema cf. também Villegas (1993). Por outro lado, tratando especificamente das políticas públicas, Coutinho (2014b, p.18), partindo da conceituação feita por Draibe (2001, pp. 35-37), na ciência política, entende por eficácia "a relação entre as características e qualidade de um programa de uma política pública, de um lado, e os resultados a que chega, de outro. 'Assim, será mais eficaz - atingirá seus resultados em menor tempo, com menor custo e com mais alta qualidade - aquele programa que se apoiar em processos e sistemas adequados de implementação"'. A ideia efetividade, por sua vez, refletiria "a intensidade em que as práticas e comportamentos sociais sofreram alterações após a promulgação de uma certa norma jurídica. Isto é, a efetividade diz respeito à medida da real efetivação da norma jurídica (um direito econômico e social, por exemplo) que se quer ver aplicada por meio de uma política pública ou, em outras palavras, o desempenho concreto da função social de tal norma". A título exemplificativo, se observarmos os dispositivos da Lei Maria da Penha (Lei 11.340/2006, que cria mecanismos para coibir a violência doméstica e familiar contra a mulher), a eficácia da lei poderia ser avaliada na medida de implementação das medidas protetivas, entre outras, de identificação pelo juiz da situação de vulnerabilidade e de inclusão nos cadastros de programas assistências (Art. $9^{\circ}$ ). De outra ordem é a avaliação do impacto da lei, por exemplo, nas taxas de homicídios de mulheres, como apresentado pelo estudo do IPEA (CERQUEIRA et al, 2015), que construiu um cenário contrafactual para avaliar a efetividade da lei pautado na seguinte questão "se não houvesse a lei, as taxas de homicídios teriam crescido mais do que o que foi observado?". Assim, o estudo concluíu que a efetividade da Lei Maria da Penha, com potenciais efeitos para dissuadir a violência doméstica, decorre do aumento do custo esperado da punição, em razão tanto das condições protetivas implementadas a partir dos dispositivos legais criando condições de segurança para que ocorressem denúncias, quanto pelo aperfeiçoamento da prestação jurisdicional que alcançou condições para uma justiça criminal apta neste tipo de atendimento. Como contra exemplo, a eficácia em sentido estrito de uma lei pode ser causa de sua própria ineficácia em sentido amplo como no caso da Lei Antidrogas (Lei 11.343/2006): o tráfico de drogas seguiu crescendo depois dessa lei, mas houve uma "explosão de prisões", ou seja, o efeito da lei não teve impacto na redução de tráfico e ainda aumentou a lotação carcerária (BOITEUX et al., 2009), A hipótese mais recorrente de estudos sobre esse último tema fortalece a tese de que a partir da lei, seguiu uma crescente de encarceramento de usuários tomados pela lei
} 
participação social ${ }^{12}$, o tema proposto para o presente trabalho encontra limite na análise das IPs consideradas como uma política pública em si - ou seja, com formas jurídicas adequadas para sua criação, com objetivos específicos de participação, com destinação de recursos próprios para sua realização, prazos, formulações e decisões entre alternativas de implementação da participação, prestação de contas, etc; e, sobretudo, em regras específicas de funcionamento da participação.

Nesse sentido, este trabalho não pretende analisar o impacto de IPs para eficácia das políticas setoriais, por exemplo, de alcance finalístico de políticas ambientais específicas como os objetivos da política de destinação de resíduos sólidos (ex. aumento de taxa de reciclagem). Também não pretende avaliar, pelo critério de efetividade, os efeitos sociais desejados desse mesmo tipo de política, como o objetivo mais amplo de preservação do meio ambiente (avaliando, por exemplo, indicadores de áreas contaminadas) ou ainda de redução de desigualdades sociais decorrentes de tais políticas (ex. quando a política de gestão de resíduos é implementada em parceria com cooperativas de catadores).

Com foco no Poder Executivo Federal, este trabalho busca demonstrar que há um fortalecimento da democracia participativa por meio do desenvolvimento de instrumentos jurídicos de transparência, participação e controle social na condução das políticas públicas durante as duas últimas décadas. Por meio da análise de institucionalização de uma ampla política de participação social para a gestão pública, sobretudo, desde o início dos anos 2000, o trabalho sugere que, se de um lado, é possível admitir uma Reforma do Estado Participativa, ainda em curso, sua principal característica consiste no fortalecimento da oferta de mecanismos de legitimidade de proximidade (potencial de

como "traficantes", reforçando o descompasso entre os objetivos do texto legal e o tipo penal, especialmente do Art. 33 da lei, com a realidade social da rede de tráfico de drogas com diferentes papéis entre seus integrantes - dos mais insignificantes ao topo do "comando" da rede.

${ }^{12}$ Avritzer (2011, p. 13) aponta duas razões principais para o foco na questão da efetividade: (i) crescente associação entre participação e políticas públicas, em especial no caso brasileiro por causa das experiências deliberativas disseminadas em áreas como saúde, assistência social e políticas urbanas; e (ii) preocupação de caráter mais teórico em relação aos efeitos da deliberação. O texto ainda não publicado "The More Participated, the Better? Effects of Participation on Quality of Policies", de Carolina Galais, Pau Alarcón e Fabiola Mota, apresentado durante o $23^{\circ}$ Congresso Internacional de Ciência Política (IPSA), em julho de 2014, em Montreal (Canadá), reúne uma vasta revisão da literatura focada especialmente nos efeitos da participação, para os quais os autores dividem entre (i) impactos diretos para os cidadãos participantes, entre os quais satisfação com a prestação de serviços públicos; (ii) efeitos para a sociedade, dos quais destaca redução de desigualdades sociais e redução da pobreza e (iii) impactos para as políticas públicas, como efeitos na implementação. 
mobilização e presença da participação) na condução das políticas públicas. Por outro lado, a análise da arquitetura jurídica da política de participação social, quando atenta ao fenômeno de procedimentalização do direito, demonstra que existem possibilidades ainda inexploradas para melhorias na gestão da participação e promoção da legitimidade de proximidade, por meio do fortalecimento da rede de mecanismos de legitimidade funcional. Essa análise privilegia o potencial de intercompetências e internormatividades 
ao desdobrar as regras de participação entre formas de promoção de governabilidade $^{13} \mathrm{e}$ de governança ${ }^{14}$ junto à Administração Pública.

${ }^{13}$ Segundo Faria "Em termos conceituais a noção de governabilidade tem sido associada à incapacidade de um governo ou de uma estrutura de poder formular e de tomar decisões no momento oportuno, sob a forma de programas econômicos, políticas públicas e planos administrativos, e de implementá-las de modo efetivo, em face de uma crescente carga de expectativas, de problemas institucionais, de clivagens políticas, de conflitos sociais e de demandas econômicas" (2002, pp. 117-119). Nesse ponto é útil a conceituação de governabilidade trazida por Nogueira (1995, p.105): "Diferentemente do conceito de representação - que privilegia a capacidade que têm os governados de controlar a ação dos governantes e deste modo participar do governo -, o conceito de governabilidade costuma focalizar, naquela relação, o movimento inverso, insistindo na capacidade que têm os governantes de tomarem decisões que atendam demandas efetivas dos governados e de viabilizarem a reprodução das condições de preservação do poder. Visto desse ângulo, o conceito de governabilidade colide frontalmente com a idéia de participação, pois acaba por interpretá-la como foco gerador de propostas e reivindicações incômodas, potencialmente opostas à racionalidade governamental. Não por acaso, o conceito emergiu na ciência política pela ótica da "ingovernabilidade", com um claro viés conservador, já que dirigido basicamente para a justificação de procedimentos destinados à redução dos fatores e exigências interpostas pela sociedade ao "bom" funcionamento do sistema político, ou, para falar com termos mais rigorosos, destinados a diminuir os custos de legitimação do sistema político." Enquanto os primeiros usos do termo "governabilidade" são datados em 1820 (Rosanvallon, 2008 p. 286), o desenvolvimento do conceito em referência na explicação de Nogueira ficou marcado entre as décadas de 70 e 80 . Sobre a "ingovernabilidade" no contexto do "renascimento das teorias conservadoras da crise", com destaque para o contexto de crise do Estado de bem estar social, ver Claus Offe (1984, pp. 236 e ss). Se no contexto temporal específico da década de 70/80 a relação entre poder social e autoridade política trazia a questão da "ingovernabilidade" como patologia estrutural entre Estado paternalista e sociedade capitalista, como fio condutor de desintegração social, e não apenas como sintoma das expectativas sociais não atendidas; no atual contexto de Estado pós-Moderno ou funcional, a "ingovernabilidade" é ponto de partida e não de chegada na relação entre governantes e governados. Assim, parte-se para uma ressignificação do funcionamento político pela consideração da necessidade de atenção à complexidade dos conflitos políticos tais quais vivenciados a partir de junho de 2013, por meio de avanços em propostas ainda que parciais de construção de consenso com participação, que possam ser incentivadas em diversas frentes, e não resignação do exercício da representação apesar da falta de consenso. Essa proposta pode ir além de saídas para conjunturas datadas de "crises de governabilidade", tal qual a que atinge as instituições políticas brasileiras ao final do primeiro mandato da Presidenta Dilma Rousseff, oferecendo riscos sistêmicos para instâncias de representação políticas tradicionais, mas também para a cultura democrática construída pelo país desde a redemocratização. Cf. Marcos Nobre (2013, p. 11), da virada nacional-desenvolvimentista (controle da inflação) para a social-desenvolvimentista (redução de desigualdades), a persistente ideologia de naturalização do "peemedebismo" agrava o problema do "bordão da governabilidade": reduzir desigualdades a custo do peemedebismo não pode significar ganho democrático. Há um "clamor por aprofundamento da democracia", além da transição democrática com estabilização econômica e política (CF/1988), exigindo uma mudança de cultura institucional e modo de vida: "Formalmente a redemocratização parece encerrada", mas "a democracia no país ainda é pouco democrática de fato (...) não é apenas funcionamento das instituições políticas formais (...) é uma forma de vida que penetra fundo no cotidiano, que se cristaliza em uma cultura política pluralista". Sem ignorar a importância de teorias que possam ir além de análises das instituições formais, o conceito de "governabilidade" que será utilizado nesta tese se afasta das conceituações datadas, sobretudo como receitas de políticas conservadoras para saídas de crises políticas como na origem do termo datado entre as décadas de 70 e 80 , e será simplificado à promoção de "condições políticas" como forma de correção de "falhas políticas", em contraponto à ênfase nas correções de "falhas econômicas" preponderantes nas leituras sobre reforma gerencial características da década de 90, baseadas em receitas externas

${ }^{14}$ Sobre o "paradigma da governança", Santos (2011, p. 19) discute, em especial, o problema da governança neoliberal, para a compreensão da superação da crise de legitimidade. Segundo Santos (2011, p. 21), com o surgimento da matriz da governança que remonta a busca por legitimidade apontada pelo movimento estudantil, seguido do movimento feminista e ecológico, a partir da década de 70, "os últimos trinta anos podem, assim, resumir-se na seguinte sequência de conceitos: da legitimidade à governabilidade, da governabilidade à governança" (grifos nossos). Por essa perspectiva, a crise de legitimidade foi transformada em crise de governabilidade, a partir do entendimento de que não era a falta de inclusão social que gerava crise social, mas o excesso de possibilidades de reivindicações permitidas a partir de um modelo de Estado paternalista. A matriz da governança neoliberal surge para "reconstruir a governabilidade de 
Nesse sentido, além de uma análise teórica sobre o papel do direito na institucionalização e estruturação da participação social em políticas públicas, a tese contemplará um mapa legal dos instrumentos normativos (leis, decretos e resoluções) que instituem conselhos e conferências de políticas públicas ambientais na Administração Pública Federal (APF). Pretende-se, com este mapeamento normativo temático, apresentar de que modo as regras e os procedimentos que disciplinam as instituições participativas ambientais, notadamente conselhos e conferências, organizam a dimensão jurídica das instituições participativas em aspectos de legitimidade funcional da ação governamental, que se desdobram em condições de governabilidade (capacidades políticas) e governança (capacidades administrativas), que também podem ser características de outras políticas públicas temáticas com participação social no Brasil.

Assim, a pesquisa foi estruturada, além desta introdução, em três etapas. Estas correspondem, em conjunto, ao desenvolvimento da tese.

O primeiro capítulo explora uma abordagem teórica situada entre a ciência política, a administração pública, as políticas públicas e o direito, para estudar o processo de institucionalização da participação social no âmbito do Poder Executivo Federal, do

maneira a transformá-la numa concepção alternativa da legitimidade" (SANTOS, 2011, p. 22). Em outras palavras, para resolver ao mesmo tempo a crise de legitimidade e de governabilidade, surge um modelo de redução do tamanho do Estado, de descentralização, e a consequente reformulação dos espaços de participação em redes e esferas não estatais. Para uma perspectiva cética conceitual e conjuntural da ideia de "governança", cf. Claus Offe (2009). Offe apresenta três principais críticas à teoria e prática da governança: (i) Primeiro, quanto à imprecisão do conceito, que abrangeria os mais diversos fenômenos, criando muitas zonas cinzentas e que, por isso, teria pouco poder explicativo da realidade; (ii) Segundo, quanto a certa retórica harmonizadora envolvendo o conceito, que se reportaria apenas a adjetivos positivos (transparente, legítimo, não-corrupto, horizontal, etc.), e que, ao cabo, tenderia a ignorar questões de poder, distribuição e conflito; (iii) Por fim, quanto à despolitização da abordagem, que daria pouca atenção ao significado do conflito de interesses e valores nas arenas de negociação. No Plano Diretor da Reforma do Aparelho do Estado (FERNANDES, 1998) para a promoção da reforma gerencial, a questão da governança da "máquina administrativa" - definida como "sua capacidade administrativa de governar com efetividade e eficiência, voltando a ação dos serviços do Estado para o atendimento dos cidadãos" ou o aumento da governança entendido como o fortalecimento de "sua capacidade de implementar de forma eficiente políticas públicas"-, prevaleceria sobre as questões da ordem da "governabilidade" - tratada como "poder para governar, dada sua legitimidade democrática e o apoio com que conta na sociedade civil" -, que se afastavam das preocupações daquela conjuntura, ainda que "o aumento da governabilidade, ou seja, do poder do governo, graças à existência de instituições políticas que garantam uma melhor intermediação de interesses e tornem mais legítimos e democráticos os governos, aperfeiçoando a democracia representativa e abrindo espaço para o controle social ou democracia direta" (BRESSER-PEREIRA, 1998). A proposta do presente trabalho, contudo, entende que o fortalecimento das capacidades administrativas do Estado voltadas à promoção da eficiência na implementação das políticas públicas não pode prescindir do fortalecimento de suas capacidades políticas, promovidas pela participação da sociedade civil junto ao aparelho do Estado. 
ponto de vista das leituras sobre Reforma do Estado no Brasil, desde a Constituição de 1988. Por revelar uma reconfiguração nas características estabelecidas para a ação do Estado, a institucionalização de IPs e sua correspondente racionalidade jurídica, indica a atualização da caracterização de uma "Reforma do Estado Participativa", ainda em curso. Trata-se, de um lado, da contextualização de processos participativos pela análise mais ampla de transformações incrementais e fragmentadas da gestão pública, desde a Reforma Gerencial da década de 90. Por outro lado, do ponto de vista de "marcos legais" de destaque para a institucionalização da participação social, sobretudo a partir dos anos 2000, alguns dos processos participativos desenvolvidos junto à Administração Pública passaram a ser mais bem definidos como Instituições Participativas (IPs), caracterizando mudanças estruturais para a agenda da gestão pública.

No segundo capítulo, explora-se uma abordagem teórica interdisciplinar para descrever IPs para diferentes políticas públicas temáticas, a partir do mapa normativo dessas instituições. Busca-se uma análise da estrutura legal que possa representar tanto a participação social como uma política pública, quanto como o direito pode descrever a participação social de uma política pública temática específica em termos de direito à participação (objetivos das regras), regras de participação (funcionamento da participação em curso) e direito da participação (regras como resultados da participação).

No capítulo terceiro, apresenta-se uma análise temática que suscitou os estudos teóricos e o mapeamento legal: a análise da arquitetura jurídica de IPs na política ambiental. A temática ambiental é exemplo emblemático para tratar da complexidade característica da relação do direito e a política pública de participação social. Para o objetivo desta tese, possibilita tratar especialmente de IPs tanto do ponto de vista quantitativo, quanto do tempo de sua institucionalização e do escopo de descentralização federativa. Na medida em que é sugerida uma tendência em considerar agências da burocracia estatal, como o Ministério do Meio Ambiente (MMA), institucionalmente abertos à politização nos processos decisórios de políticas públicas, ${ }^{15}$ justamente pela própria natureza participativa de sua criação, sugere-se que a análise institucional a partir do MMA possa ser, em futuras agendas de pesquisa, questionada do ponto de vista prático

\footnotetext{
${ }^{15}$ Conforme já destacado durante a pesquisa de mestrado (SPECIE, 2008), a ideia de abertura do MMA à participação da sociedade civil, por exemplo, aparece na comparação levantada por Coelho (2004, p. 276) sobre a tendência de maior abertura do MMA à participação desses atores em relação a outros ministérios.
} 
conforme a teoria proposta. Apesar da arquitetura jurídica porosa à participação social, questionamentos recentes sobre alegados retrocessos na legitimidade democrática dos processos participativos para a política ambiental (ex. processo de construção da usina hidrelétrica de Belo Monte $)^{16}$ colocam em destaque a reflexão tanto sobre a efetividade do direito à participação, quanto das condições de implementação das regras de participação.

Ao final, retomando os modelos teóricos e os mapeamentos legais discutidos nos capítulos 2 e 3 conclui-se pela possibilidade de uma arquitetura jurídica que possa caracterizar a participação social como uma política pública para outras áreas temáticas além da ambiental. Se, de um lado, pela ampliação, diversificação e capacidade de mobilização de IPs, a legitimidade de proximidade é fortalecida; por outro lado, o complexo cipoal de instrumentos para a gestão de IPs ainda apresenta desafios para a promoção de sua legitimidade funcional. Tais desafios podem ser superados a partir de agendas de pesquisa futuras que explorem os efeitos da implementação de regras de participação.

\footnotetext{
${ }^{16}$ Cf. Franco e Feitosa (2013). V. também Fleury e Almeida (2013). Em especial sobre o processo participativo em audiências públicas nesse caso, cf. o relatório de pesquisa do IPEA, disponível em: $\langle$ http://www.ipea.gov.br/participacao/images/pdfs/participacao/relatorio_potencial_efetividade.pdf $>$. Acesso em: nov. 2014.
} 


\section{CONSIDERAÇÕES FINAIS}

Com foco no Poder Executivo Federal, o desenvolvimento de instrumentos jurídicos de transparência, participação e controle social na condução das políticas públicas, principalmente, durante as duas últimas décadas, demonstrou um fortalecimento da democracia participativa no Brasil. Por meio da análise de institucionalização de uma ampla política de participação social para a gestão pública, sobretudo desde o início dos anos 2000, o trabalho sugere que, se é possível admitir uma Reforma do Estado Participativa, como proposta de alternativa ao paradigma preponderante da Reforma Gerencial iniciada na década de 90, sua principal característica consiste no fortalecimento, ainda em curso, da oferta de mecanismos de legitimidade de proximidade. O potencial de mobilização e de presença da participação, tanto no aspecto quantitativo e de diversidade dos participantes, quanto no alcance temporal, espacial e temático de IPs, foi observado de forma institucionalizada, principalmente, por meio da qualidade da interação institucional estabelecida pelas regras que criam e regulamentam Conselhos e Conferências Nacionais de Políticas Públicas, a exemplo das IPs em estudo na política ambiental.

A proposta de análise jurídica que a tese construiu para a política pública de participação social buscou oferecer, especialmente, uma metodologia que pudesse descrever diversos tipos de IP sob a ótica do direito. Em resumo, a metodologia proposta, abriu três frentes de análise: (i) direitos à participação (participação como objetivo das regras), em diferentes níveis de participação (acesso à informação, consulta, deliberação e fiscalização), e em distintas etapas do ciclo de vida das políticas públicas (definição de agenda, formulação, decisão e avaliação); (ii) regras de participação que organizam o funcionamento da relação entre Estado e Sociedade (ex. quem participa, em larga escala ou em grupos de especialistas); e (iii) direitos da participação (regras como objetivos da participação), característicos de instrumentos normativos que orientam a ação do Estado, em políticas temáticas específicas, por meio de resoluções, recomendações e diretrizes, incluindo impactos para atividades de elaboração legislativa no Congresso Nacional.

A investigação das quatro conferências nacionais de políticas públicas ambientais realizadas até hoje e de dois conselhos ambientais nacionais vinculados ao Ministério do Meio Ambiente (Conselho Nacional do Meio Ambiente - Conama; e o Conselho 
Nacional de Recursos Hídricos - CNRH), submetida à metodologia proposta, revelou que a política de participação social implementada na temática ambiental, ainda que incremental e fragmentada, revela direitos à participação, regras de participação e direitos da participação.

A temática ambiental é exemplo emblemático para tratar da complexidade característica da relação entre o direito e a política pública de participação social, sob a ótica de redes de legitimidade funcional, como de mecanismos de oferta de governança (capacidades administrativas) e de governabilidade (capacidades políticas). As políticas ambientais carregam a participação social como parte do núcleo da própria política pública temática. Com efeito, a política ambiental, caracterizada essencialmente como uma política de cooperação, tem sido elaborada em função de processos participativos, da esfera global à local. Ainda que não tenha sido guiada previamente por uma "Política Nacional de Participação Social", a política ambiental tem desenvolvido desde o início de sua institucionalização uma moldura jurídica para conselhos e conferências nacionais, nos moldes dos critérios estabelecidos pelo Decreto Presidencial 8.243/2014, que instituiu a PNPS, reforçando o argumento de seu caráter sistematizador de IPs.

Por fim, a metodologia proposta também permitiu conferir o impacto que o tipo de alternativas à Reforma do Estado como no caso da proposta de um paradigma participativo pode trazer para as transformações do direito contemporâneo. A análise da arquitetura jurídica da política de participação social reforça o caráter de procedimentalização do direito. Por meio da sugestão de análise de intercompetências e internormatividades, verifica-se, por exemplo, uma hiperprocedimentalização da participação social, que reforça, entre outros, o paradoxo "mais regras de participação/menos realização de objetivos das políticas de participação social". Nesse sentido, existem possibilidades ainda inexploradas para o fortalecimento da legitimidade funcional, que passam pelo aprofundamento de análises de redes de mecanismos jurídicos de IPs em outras temáticas e em diferentes IPs. 


\section{REFERÊNCIAS}

ABRÚCIO, Fernando Luiz. Três agendas, seus resultados e um desafio: balanço recente da administração pública federal brasileira. Desigualdade \& Diversidade - Dossiê Especial, pp. 119-142, 2011.

- Trajetória recente da gestão pública brasileira: um balanço crítico e a renovação da agenda de reformas. RAP Rio de Janeiro Edição Especial Comemorativa 67-86, 2007.

ABRÚCIO, Fernando Luiz; PEDROTI, Paula Maciel; PÓ, Marcos Vinicius. “A formação da burocracia brasileira: a trajetória e o significado das reformas administrativas". In: Abrúcio, F. L.; Loureiro, M. R.; Pacheco, R. (orgs.). Burocracia e política no Brasil: desafios para a ordem democrática no século XXI. Rio de Janeiro: Fundação Getulio Vargas, pp. 177-212, 2010.

ALENCAR, J. L. et al. Participação Social e Desigualdades nos Conselhos Nacionais. Sociologias, Porto Alegre, ano 15, no 32, jan./abr. 2013, p. 112-146

ALENCAR, J; COELHO, U. O Decreto sobre a Participação Social no Governo Federal e a "Polêmica Bendita". Boletim de Análise Político-Institucional / Instituto de Pesquisa Econômica Aplicada, n.6. Brasília: Ipea, 2014

ALMEIDA, Carla; TATAGIBA, Luciana. Os conselhos gestores sob o crivo da política: balanços e perspectivas. Serv. Soc. Soc., São Paulo, n. 109, p. 68-92, Mar. 2012.

ARBIX, G.; MARTIN, S. Beyond developmentalism and market fundamentalism in Brazil: inclusionary State activism without Statism. In: Workshop on "States, Development, and Global Governance". Madison: Global Legal Studies Center and the Center for World Affairs; Global Economy (WAGE), University of Wisconsin-Madison. 2010.

ARNAUD, André-Jean. Critique de la Raison Juridique: Gouvernants sans fronteires entre mondialisation et post-mondialisation. Paris: LGDJ, 2003.

O Direito entre Modernidade e Globalização: lições de filosofia do direito e do Estado. Rio de Janeiro: Renovar, 1999. 
ASSIS, Luiz Gustavo Bambini de. Processo legislativo e orçamento público: a função de controle do parlamento. Tese de Doutorado, Faculdade de Direito da Universidade de São Paulo, 2009.

AVRITZER, Leonardo e COSTA, S. Teoria Crítica, Democracia e Esfera Pública: concepções e usos na América Latina, DADOS - Revista de Ciências Sociais, vol. 47, n. 4, 2004.

AVRITZER, Leonardo, "A Qualidade da Democracia e a questão da Efetividade da Participação: mapeando o debate". In: Roberto Rocha C. Pires (org.). Efetividade das instituições participativas no Brasil: estratégias de avaliação. Brasília: Ipea, v. 7, 2011. Conferências Nacionais: Ampliando e Redefinindo os Padrões de Participação Social no Brasil. Texto para discussão 1739, Ipea, Rio de Janeiro, 2012.

Instituições participativas e desenho institucional: algumas considerações sobre a variação da participação no Brasil democrático. Opinião Pública, Campinas [online], vol.14, n.1, pp. 43-64. 2008.

BLÜHDORN, I. "Introduction - Legitimacy Crises, Efficiency Gaps, Democratic Deficits", In Blühdorn, Ingolfur (ed.). Search of Legitimacy - Policy Marking in Europe and the Challenge of Complexity. Leverkusen Opladen: Barbara Budrich Publishers, 2009.

BOITEUX, Luciana; Ela; Beatriz; Oliveira; PRADO, G. M.. Tráfico de Drogas e Constituição. Pensando o Direito, Vol.1. Brasilia-DF: Ministério da Justiça. v. 1. 122p, 2009.

BRASIL. Ministério do Planejamento, Orçamento e Gestão. Secretaria de Planejamento e Investimentos Estratégicos. Plano Mais Brasil PPA 2012-2015: Relatório de Comunicação à Comissão Mista de Planos, Orçamentos Públicos e Fiscalização do Congresso Nacional (CMO). Ministério do Planejamento, Orçamento e Gestão/SPI. Brasília: MP/SPI, $2013 b$.

BRASIL. Presidência da República. Secretaria de Políticas para as Mulheres. Plano Nacional de Políticas para as Mulheres. Brasília: Secretaria de Políticas para as Mulheres, 2013a. 
BRESSER-PEREIRA, Luiz Carlos. "Do Estado Patrimonial ao Gerencial”. In: Pinheiro, Wilheim e Sachs (orgs.), Brasil: Um Século de Transformações. São Paulo: Cia. das Letras, pp. 222-259, 2001.

A Reforma do Estado dos anos 90: Lógica e Mecanismos de Controle. Lua Nova Revista de Cultura e Política, no. 45, pp. 49-95, 1998.

Da Administração Pública Burocrática à Gerencial. Revista do Serviço Público, 47(1) janeiro-abril 1996.

BRESSER-PEREIRA, Luiz Carlos. e GRAU, Nuria C. O. O Público não estatal na Reforma do Estado. FGV e CLAD, 1999.

BRESSER-PEREIRA, Luiz Carlos; SPINK, Peter K. Reforma do Estado e administração pública gerencial. Rio de Janeiro: FGV, 2001.

BUCCI, Maria Paula Dallari. "Notas sobre a metodologia jurídica de análise de políticas públicas”. In: Cristiana Fortini, Júlio César Santos Esteves, Maria Tereza Fonseca Dias (orgs.). Políticas Públicas. Possibilidades e Limites. Belo Horizonte: Editora Forum, pp. 225-260, 2008.

. "O conceito de política pública em direito". In: Políticas Públicas: Reflexões sobre o conceito jurídico. São Paulo: Saraiva. 2006

Direito Administrativo e Políticas Públicas. São Paulo: Saraiva, 2002.

Fundamentos para uma Teoria Jurídica das Políticas Públicas. São Paulo:

Saraiva. 2013

CAMPILONGO, Celso Fernandes. "A crise da representatividade e a perda do espaço público". In: FABIANI, Emerson Ribeiro (org.). Impasses e Aporias do Direito Contemporâneo - Estudos em Homenagem a José Eduardo Faria. São Paulo: Saraiva, 2011, p. 181-190.

Crise do Estado, Mudança Social e Transformação do Direito no Brasil. São Paulo em Perspectiva, São Paulo, v. 2, n.8, p. 13-26, 1994.

CARDOSO JÚNIOR, José Celso. "O Estado Brasileiro e o Desenvolvimento Nacional: novos apontamentos para velhas questões.” José Celso Cardoso Jr. (org.). A reinvenção do planejamento governamental no Brasil. Brasília: Ipea, v.4, 2011. 
Estado, planejamento, gestão e desenvolvimento: balanço da experiência brasileira e desafios no século XXI. Texto apresentado no "Seminario sobre Neoestructuralismo y Economia Heterodoxa”. Anais, Santiago, Chile: ILPES, 2013.

CASTELLS, M. The rise of the network society. Massachusetts: Blackwell, 1997. The Internet galaxy : reflections on the Internet, business, and Society. Oxford : Oxford University Press. 2001.

. Communication power. New York: Oxford University Press. 2009.

CHADWICK, A. (2006). Internet politics: states, citizens, and new communication technologies (p. 400). Oxford University Press.

CERQUEIRA, Daniel et al. Avaliando a Efetividade da Lei Maria da Penha, Texto para Discussão TD - 2048. IPEA, 2015.

CGU. Cartilha Olho Vivo no Dinheiro Público. Um Guia para o cidadão garantir os seus direitos. Publicação da CGU. Brasília, DF, 2008.

CHEVALLIER, Jacques. L'État Post-moderne. Droit et Sociéte. Série Politique 35. Paris: LGDJ, 2008.

CICONELlo, Alexandre. Participação Social na Administração Pública Federal Desafios e Perspectivas para a criação de uma Política Nacional de Participação. (Versão Preliminar), 2012.

COELHO, RONY G S. Legislação Participativa. $36^{\circ}$ Encontro Anual da ANPOCsGT04. Controle Democráticos e Legitimidade. Aguas de Lindóia, outubro de 2012. (Disponível em: <http://portal.anpocs.org/portal/index.php?option=com_docman\& task=doc_view\&gid=7877\&Itemid=217>. Acesso em: dez 2014).

COELHO, Vera Schattan P. A democratização dos Conselhos de Saúde: o paradoxo de atrair não aliados. Novos estudos. CEBRAP, São Paulo, n. 78, July 2007.

. Brazil's Health Councils: the challenge of building participatory political institutions. IDS Bulletin. Vol. 35, n. 2, April, UK: IDS, 2004.

COUTINHO, Diogo R. Capacidades Estatais no Programa Bolsa Família: o desafio de consolidação do Sistema Único da Assistência Social. Texto para Discussão (IPEA. Brasília), v. 1, p. 1-50, 2013 b. 
. “O Direito nas Políticas Públicas”. In: Eduardo Marques e Carlos Aurélio Pimenta de Faria. (Org.). A Política Pública como Campo Multidisciplinar. 1 ed. São Paulo e Rio de Janeiro: Editora Unesp e Editora Fiocruz, v. 1, p. 181-200, 2013a.

. "O direito nas políticas sociais brasileiras: um estudo sobre o programa Bolsa Família". In: Mario G. SCHAPIRO; David M. Trubek (orgs.) Direito e Desenvolvimento um diálogo entre os Brics. São Paulo: Saraiva, 2012.

Direito Econômico e Desenvolvimento Democrático: uma abordagem institucional. Faculdade de Direito da Universidade de São Paulo. 2014b.

Entre eficiência e eqüidade: a universalização das telecomunicações em países em desenvolvimento. Revista Direito GV, vol. 1, n. 2. jun-dez, pp.137-60, 2005.

Entre Eficiência e Legitimidade: o Bolsa Família no Desafio de Consolidação do SUAS. In: Alexandre de Ávila Gomide e Roberto Rocha C. Pires. (Org.). Capacidades Estatais e Democracia: Arranjos Institucionais de Políticas Públicas. 1 ed. Brasília: IPEA, v. 1, p. 267-293, 2014a.

COUTINHO, Diogo R.; MARQUES, J.; Moretti, Julia Azevedo; PACHECO, M. G. ; ROZO, F.. O Direito nas Políticas Públicas Urbanas e Habitacionais: o uso de instrumentos urbanísticos no Município de Santo André, São Paulo. Cadernos Gestão Pública e Cidadania, v. 19, p. 58, 2014;

CUNILL GRAU, Nuria. "Modelos de Controle e de Participação Sociais Existentes na Administração Pública Federal”. In, Samuel A. Antero e Valéria Alpino Bigonha Salgado (orgs.). Participação Social: textos para discussão. Fundação Instituto para o Fortalecimento das Capacidades Institucionais - IFCI; Agência Espanhola de Cooperação Internacional para o Desenvolvimento - AECID; Ministério do Planejamento, Orçamento e Gestão - MPOG; e Editora IABS, Brasília-DF, Brasil, 2013.

DAGNINO, Evelina. Sociedade civil e espaços públicos no Brasil. São Paulo: Paz e Terra, 2002.

DAHL, Robert A. Democracy and its critics. New Haven: Yale University Press, 1989.

DINIZ, Eli. Crise Política e Governabilidade. Olhar Virtual, UFRJ, Rio de Janeiro, 2005.

DINIZ, Eli. Em Busca de um Novo Paradigma, a Reforma do Estado no Brasil dos Anos 90. São Paulo em Perspectiva, São Paulo, v. 1, n.10, p. 13-26, 1996. 
DEWEY, J. The Public and Its Problems. Swallow Press. 1954

DIJK, J. V. The one-dimensional network society of Manuel Castells. New Media \& Society. 1999.

DRAIBE, Sônia Miriam. “Avaliação de Implementção: esboço de uma metodologia de trabalho em políticas públicas", in Maria Cecilia Roxo Nobre Barreira \& Maria do Carmo Brant Carvalho (orgs.), Tendências e Perspectivas na Avaliação de Políticas e Programas Sociais, São Paulo: IEE-PUC SP, 2001.

DUNLEAVY, P., MARGETTS, H., BASTOW, S., TINKLER, J. New public management is dead - Long live digital-era governance. Journal of Public Administration Research and Theory. 2006.

DURAN, Camila Villard. A moldura jurídica da política monetária: um estudo do Bacen, do BCE e do Fed. 1. ed. São Paulo: Saraiva - DireitoGV. v. 1. 334p, 2013.

FARAH, Marta F. S, Administração Pública e Políticas Públicas. RAP - Rio de Janeiro 45(3):813-36, Maio/jun. 2011

FARIA, Cláudia Feres; RIBEIRO, Uriella Coelho. "Cap.8 - Desenho institucional: variáveis relevantes e seus efeitos sobre o processo participativo". In: PIRES, Roberto Rocha (org.). Efetividade das instituições participativas no Brasil: estratégias de avaliação. Diálogos para o Desenvolvimento. Vol. 7. IPEA, p.125-136, 2011.

FARIA, José Eduardo Campos de Oliveira. "Verbete - Legitimidade". In: NOGUEIRA, Marco Aurélio (coord.). Dicionário de Políticas Públicas. São Paulo: Unesp/Fundap, (no prelo).

. O Estado e o Direito depois da crise. São Paulo: Saraiva, 2011.

. Poucas certezas e muitas dúvidas: o direito depois da crise financeira. São

Paulo: Revista Direito GV, vol.5, n.2, p. 297-324, 2009.

. Sociologia Jurídica: Direito e conjuntura. São Paulo: Saraiva, 2008.

. O Direito na Economia Globalizada, São Paulo: Malheiros, 2000.

. Direito e Economia na democratização brasileira, Malheiros, São Paulo, 1993.

. Legalidade e legitimidade: o Executivo como legislador. Revista de Informação

Legislativa, Brasília, ano 22, n.86, abr./jun., 1985, p. 93-104. 
Poder e Legitimidade: uma introdução à política do direito. São Paulo: Perspectiva, 1976.

FEDOZZI, Luciano J. Novas instituições participativas, processos de elitização e o Orçamento Participativo de Porto Alegre. Texto apresentado no $35^{\circ}$ Encontro Anual da ANPOCS. 2012.

FERNANDES, Ciro Campos Christo. Os avanços da reforma na administração pública: 1995-1998. Brasília: Cadernos MARE, 1998.

FERRACCI, Marc; WASMER, Étienne. État moderne, État efficace: évaluer les dépenses publiques pour sauvegarder le modèle français. Paris, Odile Jacob, 2012.

FLEURY, Lorena Cândido; ALMEIDA, Jalcione. A construção da Usina Hidrelétrica de Belo Monte: conflito ambiental e o dilema do desenvolvimento. Ambient. soc., São Paulo, v. 16, n. 4, p. 141-156, Dec. 2013.

FRANCO, Fernanda Cristina de Oliveira; FEITOSA, Maria Luiza Pereira de Alencar Mayer. Desenvolvimento e direitos humanos: marcas de inconstitucionalidade no processo Belo Monte. Rev. direito GV, São Paulo, v. 9, n. 1, p. 93-114, Jun. de 2013.

FUNG, Archon. Survey Article: Recipes for Public Spheres: Eight Institutional Design Choices and Their Consequences. Journal of Political Philosohpy, 11(3), 338-67, 2003. Varieties of Participation in Complex Governance. Public Administration Review, Dec. 2006.

FOUNTAIN, J. E. Challenges to Organizational Change: Multi-Level Integrated Information Structures (MIIS). Governance and Information Technology: From Electronic Government to Information Government, (06), 1-29. 2007.

GAETANI, Francisco. As iniciativas de políticas de gestão pública do governo Lula. Revista ResPvblica n 3, pp.104-138. Brasília, 2003.

GALAIS, Carolina; ALARCÓN, Pau; MOTA, Fabiola. The More Participated, the Better? Effects of Participation on Quality of Policies, texto apresentado durante o $23^{\circ}$ Congresso Internacional de Ciência Política (IPSA), Montreal (Canadá), em julho de 2014.

GALLICCHIO, E.; CAMEJO, A.. Desarrollo local descentralización en América latina. Montevideo: Claeh, 2005. 
GERSCHMAN, Silvia. Conselhos Municipais de Saúde: atuação e representação das comunidades populares. Cad. Saúde Pública, Rio de Janeiro, v. 20, n. 6, Dec. 2004.

GOMIDE, Alexandre de Ávila; PIRES, Roberto Rocha C. "Capacidades Estatais e Democracia - abordagem dos arranjos institucionais para a análise de políticas públicas”. In, Alexandre de Ávila Gomide e Roberto Rocha C. Pires (org.). Capacidades Estatais e Democracia - arranjos institucionais de políticas públicas. Brasília: IPEA. 2014.

GRANOVETTER, M. S. The Strength of Weak Ties. American Journal of Sociology. 1973.

HABERMAS, J. Três modelos normativos de democracia. Lua Nova, nº 36, p. 39-53, 1997.

Between Facts and Norms: contributions to a discourse theory of Law and Democracy, trad. William Rehg. Cambridge, Massachusetts: The MIT Press, 1998.

HALPERN, C. "Décision". In : BOUSSAGUET, L. et al (org.). Dictionnaire des politiques publiques, 2. Ed. Paris: Presses de Sciences Po, 2006, p. 153-60.

HARGUINDEGUY, J. B. "Cycle (Policy cycle)". In : BOUSSAGUET, L. et al (org.). Dictionnaire des politiques publiques, 2. Ed. Paris: Presses de Sciences Po, 2006, p. 14852.

HELD, David. Models of Democracy, 3rd ed. Stanford: Stanford University Press, 2006. HOOD, C. A Public Management for all Seasons? Public Administration, 69, 3-19. 1991. IBGE - Instituto Brasileiro de Geografia e Estatística. Pesquisa de Informações Básicas Municipais - MUNIC, Rio de Janeiro, 2013. Disponível em: <ftp://ftp.ibge.gov.br/Perfil_Municipios/2013/munic2013.pdf>, acesso em 4 jan. de 2015.

Pesquisa de Informações Básicas Estaduais - ESTADIC, Rio de Janeiro, 2013. Disponível em: <ftp://ftp.ibge.gov.br/Perfil_Estados/2013/estadic2013.pdf>, acesso em 4 jan. de 2015.

IPEA. Participação Popular - A construção da democracia participativa. In Desafios do Desenvolvimento. Ano 8. Edição 65, 2011.

INNERARITY, Daniel G. Un mundo de todos y de nadie - Piratas, riesgos y redes en el nuevo desorden global. Barcelona: Paidós, 2013. 
JESSOP, Bob. Bringing the state back in (yet again): reviews, revisions, rejections, and redirections, International Review of Sociology, Vol 11, n 2, pp. 149-153, 2001.

. The Regulation Approach, Governance, and Post-Fordism: Alternative Perspectives on Economic and Political Change? Economy and Society, Vol. 24, n. 3, 1995.

KLIJN, E.-H. (2002). Governing Networks in the Hollow State: Contracting out, process management or a combination of the two? Public Management Review. 2002.

KERCHOVE, François Ost et de Michel van de. De la pyramide au réseau? Pour une théorie dialectique du droit, Bruxelles, Publications des Facultés universitaires SaintLouis, 2002.

LAVALlE, Adrian G. "Cap.1 - Participação: Valor, Utilidade, Efeitos e Causa". In : PIRES, Roberto Rocha (org.). Efetividade das instituições participativas no Brasil: estratégias de avaliação. Diálogos para o Desenvolvimento. Brasília: Ipea, pp. 33-42, $2011 b$.

Após a participação: nota introdutória. Revista Lua Nova, São Paulo, 84: 1323, 2011a.

LAVAlle, Adrian G.; HOUTZAGER, Peter P.; CASTEllo, Graziela. Democracia, pluralização da representação e sociedade civil, Revista Lua Nova, São Paulo, 67: 49103, 2006.

LAVAllE, Adrián Gurza; CASTELlO, Graziela; HOUTZAGER, Peter. "Civil organizations and political representation in Brazil's participatory institutions". In CORNWALL, Andrea; COELHO, Vera Schattan P. (eds.) Spaces for change: the politics of participation in new democratic arenas. Londres: Zed, 2007.

LAVALlE, Adrian Gurza; SZWAKO, José. Origens da Política Nacional de Participação Social: Entrevista com Pedro Pontual. Novos estudos. - CEBRAP, São Paulo, n. 99, p. 91-104, July 2014.

LEWANSKI, R. "Institutionalizing Deliberative Democracy: the "Tuscany laboratory'," Journal of Public Deliberation. Vol. 9: Iss. 1, Article 10, 2013.

LIMA, P. et al. Conselhos nacionais: elementos constitutivos para a sua institucionalização. Texto para discussão, TD - 1951, IPEA, 2014. 
LORENZETTI, Julia Vaz; CARRION, Rosinha Machado. Governança ambiental global: atores e cenários. Cad. EBAPE.BR, Rio de Janeiro, v. 10, n. 3, Set. 2012.

LOUREIRO, Maria Rita G.; ABRUCIO, F. L. Democracia e eficiência: a difícil relação entre política e economia no debate contemporâneo. Revista de Economia Política, v. 32, p. 615-633, 2012.

LÜCHMANN, L. H. H. 25 anos de Orçamento Participativo: algumas reflexões analíticas. Política e Sociedade, Florianópolis, v. 13, n. 28, p. 167-197, 2014.

MACHADO, Paulo Affonso Leme. Direito à informação e meio ambiente. 1. ed. São Paulo: Malheiros, 2006.

MANIN, B. "Legitimidade e Deliberação Política", In: WERLE, D. L. e MELO, R. S. (orgs.). Democracia Deliberativa. São Paulo: Editora Singular, 2007.

MASSA-ARZABE, Patrícia Helena. Dimensão jurídica das políticas públicas. In BUCCI. Políticas Públicas: Reflexões sobre o Conceito Jurídico. São Paulo: Saraiva, pp. 51-74, 2006.

MATTOS, Paulo. O Novo Estado Regulador no Brasil: Direito e Democracia. Tese de Doutorado, Faculdade de Direito da Universidade de São Paulo, 2004.

MAYNTZ, R. From government to governance : Political steering in modern societies. In International Summer Academy "From Government to GOvernance: The Case of Integrated Product Policy" (p. 3). 2003

O Novo Estado Regulador no Brasil: Eficiência e Legitimidade. São Paulo: Singular, 2006.

MELO, Rúrion. O Uso Público da Razão: pluralismo e democracia em Jürgen Habermas. São Paulo: Edições Loyola, 2011.

MICHENER, Greg. FOI Laws around the World. Journal of Democracy, v. 22, n. 2, pp. 145-159, 2011.

MILANI, Carlos R. S.. O princípio da participação social na gestão de políticas públicas locais: uma análise de experiências latino-americanas e européias. Revista de Administração Pública, v. 42, p. 551-579, 2008.

MILWARD, H. B.; PROVAN, K. G. Governing the Hollow State. J Public Adm Res Theory, 10, 359-380. 2000. 
MORAND, Charles-Albert. "Vers um droit de l'environnement souple et flexible: le rôle et le fonctionnement des principes". In: OST, François. et GUTWIRTH, Serge. Quel avenir pour le droit de l'environnement? Bruxelles: VUB, 1996

. Le droit néo-moderne des politiques publiques. Paris: LGDJ 1999.

MONÉDIAIRE, Gerard. "Droit de l'environnement et participation”, in CASILLO I. avec BARBIER R., BLONDIAUX L., CHATEAURAYNAUD F., FOURNIAU J-M., LEFEBVRE R., NEVEU C. et SALLES D. (dir.), Dictionnaire critique et interdisciplinaire de la participation, Paris, GIS Démocratie et Participation, 2013.

MULLER, Pierre. Les politiques publiques. Que sais-je? Paris: PUF, 2000.

NASCIMENTO, Rocha, Elisama et al. O papel do conselheiro municipal de saúde na fiscalização do orçamento público. Saúde debate, vol.37, no.96, pp. 104-111, Mar. 2013.

NASSER, Salem H. Fontes e Normas do Direito Internacional: um Estudo Sobre a Soft Law. São Paulo: Editora Atlas, 2006.

NASSUNO, Marianne. Burocracia e Participação: a experiência do Orçamento Participativo em Porte Alegre. Tese de Doutorado em Sociologia. Universidade de Brasília. 2006.

NOBRE, Marcos e TERRA, Ricardo (orgs.). Direito e democracia. Um guia de leitura de Habermas. São Paulo: Malheiros, 2008.

. "Participação e deliberação na teoria democrática: uma introdução". In: COELHO, Vera Schattan P.; NOBRE, Marcos (orgs.). Participação e Deliberação: Teoria Democrática e Experiências Institucionais no Brasil Contemporâneo. São Paulo: Editora 34, 2004, pp. 21-40.

Choque de democracia - Razões da revolta. Companhia das Letras (edição Digital). 2013a.

Imobilismo em movimento: Da redemocratização ao governo Dilma. São Paulo: Cia das Letras, 2013b.

NOGUEIRA, Marco Aurélio. Para uma governabilidade democrática progressiva. Lua Nova [online]. 1995, n.36, pp. 105-128. Disponível em: $<$ http://www.scielo.br/scielo.php?script=sci_arttext\&pid=S010264451995000200007\&l ng=en\&nrm=iso $>$. Acesso em: set 2013. 
O’DONNELL, Guillermo. Accountability Horizontal e Novas Poliarquias. In: Lua Nova, No. 44, pp. 29-54, 1998.

OFFE, Claus. Problemas Estruturais do Estado Capitalista. Rio de Janeiro: Tempo Brasileiro, 1984.

. Governance: An "Empty Siginifier”?. Constellations. Vol 16. No 4, 2009.

OCDE. Manual sobre informação, consulta e participação na formulação de políticas públicas. Organização para a Cooperação e o Desenvolvimento Econômico. Brasília: MP, SEGES, 2002.

OECD. Report on impact of the emerging information society on the policy development process and democratic quality. 1999.

OFFE, Claus. Governance: An "Empty Siginifier”?. Constellations. Vol 16. No 4, pp. 550-562, 2009.

Problemas Estruturais do Estado Capitalista. Rio de Janeiro: Tempo Brasileiro, 1984.

ONU. Our Global Neighbourhood: The Report of the Commission Global Governance. Oxford: Oxford University Press, 1995.

ONU, Reference document on the participation of civil society in United Nations conferences and special sessions of the General Assembly during the 1990s, preparado pelo Office of the President of the Millennium Assembly 55th session of the United Nations General Assembly, Version 1. Ago. 2001. (Disponível em: <http://www.un.org/ga/president/55/speech/civilsociety1.htm>, acesso em out 2011)

OSBORNE, S. P. The New Public Governance? Public Management Review, 8(3), 377387. 2006.

OXHORN, P. Cidadania como consumo ou cidadania como agência: uma comparação entre as reformas de democratização da Bolívia e do Brasil. Sociologias, Porto Alegre, v. 12, n. 24, Aug. 2010

PETERS, B. G.; PIERRE, J. Introduction: The Role of Public Administration in Governing. In Handbook of Public Administration (pp. 1-9). 2003 
PIRES, Roberto C. et al. Considerações sobre a integração das instituições participativas ao ciclo de gestão de políticas públicas: subsídios à formulação de um sistema de participação. Nota técnica n. 3, Ipea, Brasília, 2012.

PIRES, Roberto C.; VAZ, Alexander. Participação social como método de governo? Um mapeamento das interfaces socioestatais no governo federal. Texto para discussão 1707 , Ipea, Brasília, 2012.

PIRES, Roberto Rocha C. (org.). Efetividade das instituições participativas no Brasil: estratégias de avaliação. Brasília: Ipea, v. 7, 2011.

PIRES, Roberto et al. Considerações sobre a integração das instituições participativas ao ciclo de gestão de políticas públicas: subsídios à formulação de um sistema de participação. Nota técnica n. 3, Ipea, Brasília, 2012.

POGREBINSCHI, Thamy (coord.). Entre Representação e Participação: As conferências nacionais e o experimentalismo democrático brasileiro. Relatório de Pesquisa- versão integral. Projeto Pesando o Direito. 2010.

POGREBINSCHI, Thamy; SANTOS, Fabiano. Participação como Representação: $O$ Impacto das Conferências Nacionais de Políticas Públicas no Congresso Nacional. In DADOS - Revista de Ciências Sociais, Rio de Janeiro, vol. 54, no 3, 2011, pp. 259 a 305. POLLITT, C. Justification by Works or by Faith?: Evaluating the New Public Management. Evaluation. 1995.

POWELL, W. Neither Market nor Hierarchy: Network Forms of Organization. Research in Organizational Behavior, Vol. 12. 1990.

RAIS, Diogo. A Sociedade e o Supremo Tribunal Federal: o caso das audiências públicas. 1. ed. Belo Horizonte: Editora Fórum, v. 1. 179p, 2012.

REIS, Marcos Antônio. Cidadania Legislativa: um balanço dos dez anos da Comissão de Legislação Participativa da Câmara dos Deputados. Brasília, n. 8, pp. 34-55, 2012. Disponível em: <http://elegisbr.com/cefor/index.php/e-legis/article/viewFile/85/102〉. Acesso em: dez. de 2014.

REZENDE, R. M. Democracia Administrativa e Princípio da Legalidade: A Política Nacional de Participação Social constitui matéria de lei ou de decreto? Brasília: Núcleo de Estudos e Pesquisas/ CONLEG/Senado, Outubro/2014. Texto para Discussão nº 158. Disponível em: <www.senado.leg.br/estudos> Acesso em: nov.2014. 
RIPLEY, Randall. "Stages of the policy process". In: Daniel C. McCool (ed.). Public policy theories, models, and concepts: an anthology. New Jersey: Prentice Hall, 1995.

ROSANVALLON, Pierre. La Légitimité démocratique. Paris: Seuil, 2008.

SANCHEZ BADIN, M. R.; VITALE, D. C. V. R.; S.; SPÉCIE, P. A repolitização em questão: o exemplo da proposta de reforma da ONU para a participação da sociedade civil. Estudos Afro-Asiáticos, v. 32, p. 277-308, 2013.

SALINAS, Natasha Schmitt Caccia Salinas. A Lei como Instrumento de Ação Governamental: fundamentos teóricos, limites e potencialidades. Revista da Faculdade de Direito da FMP, n. 8, pp. 129-155, 2013.

SANTOS, Boaventura de Souza. "A crítica da governança neoliberal: o Fórum Social Mundial como política e legalidade cosmopolita subalterna". In FABIANI, Emerson Ribeiro (org.). Impasses e Aporias do Direito Contemporâneo - Estudos em Homenagem a José Eduardo Faria. São Paulo: Saraiva, p. 15-50, 2011.

. Democratizar a Democracia - os caminhos da democracia participativa, Porto: Afrontamento, 2003.

Toward a new common sense: law, science and politics in the paradigmatic transition, New York, Routledge, 1995.

. The Law of the Opressed: Construction and Reproduction of Legality in Pasargada. Law \& Society Review, Vol. 12, No. 1, Autumn, 1977.

SCHUARTZ, Luis Fernando. Universalização dos fins e particularização dos meios: política social e significado normativo dos direitos fundamentais. São Paulo: Revista Direito GV, vol.5, n.2, p. 359-376, 2009.

SCHUMPETER, Joseph (1984). Capitalismo, Socialismo e Democracia. Rio de Janeiro: Zahar.

SILVA, Adriana Campos et alli. Por um sistema de ouvidorias públicas: possibilidades e obstáculos. Série Pensando o Direito, vol. 42. Brasília: Ministério da Justiça, 2012.

SILVA, V. S. V. A Sociedade Civil nas Relações Internacionais: participação de ONGs em três conferências das Nações Unidas da década de 1990: UNCED (Brasil/1992); ICPD (Egito/1994) e WSSD (Dinamarca/1995). Dissertação de Mestrado em Ciência Política. Universidade de São Paulo, 2006. 
SOUZA, Celina. Construção e Consolidação de Instituições Democráticas: papel do orçamento participativo. São Paulo em Perspectiva, 15(4) 2001.

SOUZA, Clóvis Henrique L. A que Vieram as Conferências Nacionais? Uma análise dos objetivos dos Processos realizados entre 2003 e 2010. Texto para discussão, TD 1718, IPEA, 2012.

SPÉCIE, P. Apresentação Temática - Amicus Curiae e Audiência Pública na Jurisdição Constitucional. Revista Brasileira de Estudos Constitucionais, v. 6, p. 837-843, 2012. Política externa e democracia: reflexões sobre o acesso à informação na política externa brasileira a partir da inserção da temática ambiental no caso dos pneus entre o Mercosul e a OMC. Dissertação (Mestrado). Faculdade de Filosofia, Letras e Ciências Humanas da Universidade de São Paulo, São Paulo, 2008.

Rhodes, R. A. W.. Understanding Governance: Ten Years On. Organization Studies. 2007.

. Recovering the "craft" of Public Administration. Participation, 38(1), 11-14. 2014

STEIN, J. G. The Cult of Efficiency (p. 328). House of Anansi Press. 2002.

STREECK, Wolfgang. As crises do capitalismo democrático. Novos estudos. CEBRAP, São Paulo, n. 92, p. 35-56, Mar. 2012.

SUNDFELD, Carlos Ari; ROSILHO, André Janjácomo. Direito e Políticas Públicas: Dois Mundos? In: Carlos Ari Sundfeld; André Rosilho. (Org.). Direito da Regulação e Políticas Públicas. 1ªed.São Paulo: Malheiros Editores, 2014, v., p. 45-79.

TATAGIBA, Luciana A institucionalização da participação: os conselhos municipais de políticas públicas na cidade de São Paulo. In: AVRITZER, L. (org.). A participação em São Paulo. São Paulo: UNESP, 2004, p. 323-370.

TSAI, W. Social Capital, Strategic Relatedness and the Formation of Intraorganizational Linkages. Strategic Management Journal, 21(9), 925-939, 2000.

VAZ DA SILVA, Vania Sandeléia. A concentração geográfica da sociedade civil global: análise da distribuição das sedes das organizações não governamentais credenciadas para as conferências sociais globais da Organização das Nações Unidas. 2011. Tese 
(Doutorado em Ciência Política) - Faculdade de Filosofia, Letras e Ciências Humanas da USP-SP.

A sociedade civil nas relações internacionais: participação de ONGs em Três conferências das Nações Unidas na década de 1990: UNCED (Brasil/1992): ICPD (Egito/1994) e WSSD (Dinamarca/1995). Dissertação (Mestrado em Ciência Política) Universidade de São Paulo, 2006.

VIEGAS, Weverson da Silva. $O$ direito à informação como pressuposto para a participação popular no estatuto da cidade. Revista da Faculdade de Direito de Campos, ano IV, no 4, 2003-2004.

VILLEGAS, Maurício. La eficácia Simbólica del Derecho, Santafé de Bogotá, Universidad de los Andes, 1993, pp. 94-100

VITALE, Denise et al. Democracia Global: A Sociedade Civil Do Brasil, Índia E África Do Sul Na Formulação Da Política Externa Ambiental De Seus Países. RGSA - Revista de Gestão Social e Ambiental Maio. - Ago. 2009, v.3, No 2, p. 160-178 (p.167). Disponível em: www.rgsa.com.br. Acesso em: out. 2014.

. "Democracia Direta e poder local". In: COELHO, Vera Schattan P.; NOBRE, Marcos (orgs.). Participação e Deliberação: Teoria Democrática e Experiências Institucionais no Brasil Contemporâneo. São Paulo: Editora 34, 200.

. "Direito, democracia e políticas públicas: entre legitimidade e eficácia". In: FABIANI, Emerson Ribeiro (org.). Impasses e Aporias do Direito Contemporâneo Estudos em Homenagem a José Eduardo Faria. São Paulo: Saraiva, 2011.

VON HALDENWANG, Christian, Mapping Legitimation: How Do States Manage Situations of Stress and Change? Texto apresentado durante a Conferência "IPSA-ECPR Joint Conference: Whatever Happened to North-South?”, realizada na Universidade de São Paulo entre os dias 16 e 19 de fevereiro de 2011. (Disponível em SSRN: <http://ssrn.com/abstract=1907722 orhttp://dx.doi.org/10.2139/ssrn.1907722>. Acesso em: out. 2014).

UZZI, B. Towards a Network Perspective on Organizacional Decline. International Journal of Sociology and Social Policy. 1997.

WAKSBERG-GUERRINI, A.; AIBAR, E.. Towards a Network Government? A Critical Analysis of Current Assessment Methods for E-Government. (M. A. Wimmer, J. Scholl, 
\& A. Gronlund, Eds.)Electronic Government: 6th International Conference, (EGOV 2007). Springer Berlin/Heidelberg. 2007.

WEBER, M. Legitimate Authority and Bureaucracy. In Organization Theory: Selected Readings (Vol. trans. 196, pp. 3-15). 1924.

Economía y Sociedad. México, Fondo de Cultura Económica, 2004.

WELP, Y., URGELL, F., \& AIBAR, E. From bureaucratic administration to network administration? An empirical study on e-government focus on Catalonia. Public Organization Review, 7, 299-316. 2007 
